\title{
Reaction of Aldehydes and Ketones with Dichloroisopropoxyborane. Comparison of the Reducing Characteristics of Isopropoxyborane Derivatives
}

\author{
Jin Soon Cha," Se Jin Yu, Min Young Roh, Seung Jin Park, Ja Eun Yi, and Oh Oun Kwon \\ Deparment of Chemistry, Ietmgnam Lnwersity, Gyongsan 712-749, Korea. *E-mail jscharân.ac.kr \\ Received Febrtary,+ 2008
}

Key Words : Dichloroisopropoxỵborane. MPV type reaction. Reduction of organic compounds. Isopropoxyboranes

Recently. we reported that boron triisopropoxide reduces simple aldehydes and ketones at $25^{\circ} \mathrm{C}$ or in refluxing THF under a slow stream of nitrogen. ${ }^{1}$ This is the furst example that boron alkoxides react with carbonyl compounds in a Meerwein-Ponndorf-Verley (MPV) type fashion. ${ }^{2}$

In general. the reaction of boron triisopropoxide is much milder than that of aluminum triisopropoxide. Boron triisopropoxide only can reduce aliphatic aldehydes and ketones anong the carbonyl conpounds. whereas the aluminum reagent reduces most carbonyl conpounds irrespective of its structure. ${ }^{2 d}$ Therefore, the reagent night serve as a comparative partner of aluminum triisopropoxide. However, side reactions are significant under the reaction conditions and hence yields become lower as the reaction goes on ${ }^{3}$ Furthermore. in these reactions the acetone formed should be removed from the equilibrium mixture by a slow stream of nitrogen: otherwise, the yields are often quite low. In these respects. we need to develop other boron alkoxide derivatives. which can overcome such difficulties. In the course of such efforts. we found that dichloroisoproposyborane appears to be one of possible candidates. We wish now to report the reducing characteristics of dichloroisoproposyborane in the reaction of selected organic compounds containing representative functional groups.

In Table 1, the reactivity of dichloroisoproposyborane toward various aldehydes is summarized and compared to those of boron triisoproxide. As compared in the Table. the reactivity of dichloroisopropoxyborane is found to be quite different from that of boron triisoproxide. Thus, dichloroisoproposyborane reduced both aliphatic and aromatic aldehydes readily to the corresponding alcohols within 1 or $3 \mathrm{~h}$ at $25^{\circ} \mathrm{C}$, whereas boron triisoproxide showed a much lower reactivity toward aliphatic aldehydes and actually no reactivity toward aromatic ones. In addition to that, the side reactions. which are significant in the reaction of aldehydes with boron triisoproxide under a strean of nitrogen. were not accompanied in this reaction even in the presence of acetone formed.

Dichloroisoproposyborane shows also quite similar trend in the reduction of ketones, as shown in Table 2 . The reactivity of the reagent toward ketones is much stronger than that of boron triisoproxide. Simple ketones were readily reduced. but some hindered alkyl and aryl ketones very slowly and hence could not be employed for this purpose under these reaction conditions.

However. the reagent is absolutely inert toward other organic functional groups. such as acid chlorides. carboxylic acids. anides. esters, nitriles. etc. Therefore, we will explore in more detail the possibility achieving a selective reduction of particular organic functional groups.

It is generally accepted that the MPV type reactions using boron triisopropoxide proceeds wia a complex in which both the carbonyl compound and the reducing alcohol are bound to the boron ion. Thus, the carbonyl is activated upon coordination to $\mathrm{B}$ (III). followed by a lydride transfer from the alcoholate to the carbonyl group via a six-membered transition state. ${ }^{\text {th }}$ From this mechanistic point of view. the coordinating capacity of boron atom to the carbonyl oxygen

Table 1. Reaction of Aldehydes with Dichloroisopropoxyborane in Methylene Chloride at $25^{\circ} \mathrm{C}$

\begin{tabular}{|c|c|c|c|}
\hline \multirow{2}{*}{ Compound } & \multirow{2}{*}{ Time (h) } & \multicolumn{2}{|c|}{ Yield of alcohol $(\%)^{p}$} \\
\hline & & $\mathrm{PrOBCl}_{2}^{b}$ & $(\mathrm{PrO}))_{\mathrm{B}} \mathrm{B}^{\mathrm{s}}$ \\
\hline \multirow[t]{4}{*}{ caproaldehyde } & 0.5 & 100 & \\
\hline & 3 & 100 & 47 \\
\hline & 24 & & 50 \\
\hline & 72 & & 45 \\
\hline \multirow[t]{3}{*}{ isobutyraldehyde } & 1 & 100 & 85 \\
\hline & 3 & 100 & 94 \\
\hline & 6 & & 79 \\
\hline \multirow[t]{3}{*}{ benzaldehyde } & 0.5 & 100 & \\
\hline & 3 & 100 & \\
\hline & 72 & & trace \\
\hline \multirow[t]{3}{*}{$p$-nitrobenzaldehyde } & 0.5 & 100 & \\
\hline & 3 & 100 & \\
\hline & 72 & & trace \\
\hline \multirow[t]{2}{*}{$p$-tolualdehyde } & 0.5 & 100 & \\
\hline & 72 & & trace \\
\hline \multirow[t]{3}{*}{$p$-chlorobenzaldehy de } & 0.5 & 96 & \\
\hline & 3 & 99.9 & \\
\hline & 72 & & trace \\
\hline \multirow[t]{2}{*}{ 2,6-dichlorobenzaldehỵde } & 0.5 & 100 & \\
\hline & 3 & 100 & \\
\hline \multirow[t]{2}{*}{$p^{p}$-methoxy benzaldehyde } & 0.5 & 68 & \\
\hline & 3 & 99.9 & \\
\hline
\end{tabular}

"Analyzed by GC with a suitable intemal standard. ${ }^{b}$ Ten "io excess reagent utilized. 'Data taken from ref. 1 . The reaction was carried out in THF under strean of nitrogen. 
Table 2. Reaction of Ketones with Dichloroisoproposyborane in Methylene Chloride at $25^{\circ} \mathrm{C}$

\begin{tabular}{|c|c|c|c|}
\hline \multirow{2}{*}{ Compound } & \multirow{2}{*}{ Time (h) } & \multicolumn{2}{|c|}{ Yield of alcohol $(\%)^{4}$} \\
\hline & & ${ }^{\mathrm{PTOBBCl}}{ }_{2}^{b}$ & $\left({ }^{(} \mathrm{PrO}\right)_{3} \mathrm{~B}^{c}$ \\
\hline \multirow[t]{3}{*}{ 2-butanone } & 0.5 & 100 & \\
\hline & 3 & 100 & \\
\hline & 24 & & 75 \\
\hline \multirow[t]{4}{*}{ 2-heptanione } & 3 & 80 & $1 \hat{3}$ \\
\hline & 6 & 85 & 18 \\
\hline & 24 & 88 & 56 \\
\hline & 72 & 99 & 97 \\
\hline \multirow[t]{2}{*}{ cyclohexanone } & 0.5 & 100 & \\
\hline & 6 & 100 & 90 \\
\hline \multirow[t]{2}{*}{ 2-methyloyclohexanone } & 0.5 & 100 & \\
\hline & 6 & $100^{d i}$ & 86 \\
\hline \multirow[t]{2}{*}{ 3-methylcyclohexanone } & 0.5 & 99 & \\
\hline & 6 & $99^{\circ}$ & 82 \\
\hline \multirow[t]{2}{*}{4 -methylcyclohexanone } & 0.5 & 100 & \\
\hline & 6 & $100^{f}$ & 81 \\
\hline \multirow[t]{2}{*}{ norcamphor } & 24 & 52 & \\
\hline & 72 & $60^{g}$ & 0 \\
\hline \multirow[t]{2}{*}{ camphor } & 24 & 50 & \\
\hline & 72 & $58^{h}$ & 0 \\
\hline \multirow[t]{3}{*}{ acetophenone } & 24 & 57 & \\
\hline & 72 & 75 & \\
\hline & 120 & 78 & trace \\
\hline \multirow[t]{2}{*}{ benzophenone } & 72 & 46 & \\
\hline & 120 & 52 & trace \\
\hline
\end{tabular}

"Analyzed by GC with a suitable internal standard. ${ }^{\mathrm{b}} \mathrm{Ten}{ }^{\circ} \mathrm{o}$ excess reagent utilized. 'Data taken from ref. 1 . The reaction was nun in THF under strean of nitrogen. "Forty six ${ }^{\circ}$ o of trons-isomer "Seventy tive ${ }^{\circ}$.

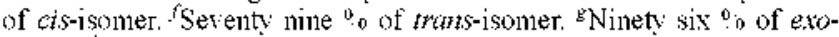
isomer. ${ }^{h}$ Fifty ${ }^{n}$ of endo-isomer.

must be one of the factors which dominate the rate of reaction. Therefore, the introduction of cllorine atom. a strong electron-withdrawing group. to boron isopropoxide increases the Lewis acidity of boron that virtually enhances the reaction rate

In conclusion. dichloroisopropoxyborane. a chlorineincorporated boron alkoxide provides an effective method for the selective reduction of aldehydes and simple ketones in the presence of other functional groups. Further the reaction of carbonyl compounds with the reagent is much faster than that of boron triisoproxide to provide a clear reaction to the corresponding alcohol stages without any effort to remove acetone formed during the reaction. ${ }^{+}$

\section{Experimental Section}

All glassware used in this study was predried at $140^{\circ} \mathrm{C}$ for at least 9 hours, assembled hot and cooled under a stream of dry nitrogen prior to use. All reactions were performed under a dry nitrogen atmosphere. All chemicals used were commercial products of the highest purity available, which were further purified by standard methods before use. $\mathrm{CH}_{2} \mathrm{Cl}_{2}$ was dried and distilled. Gas cluromatographic analy ses were carried out with a Varian 3300 cluromatograph using a $10 \% \mathrm{CW} 20 \mathrm{M}$ capillary column $(30 \mathrm{mt}$ ).

Preparation of Dichloroisopropoxyborane. To an ovendried. $100 \mathrm{~mL}$ flask with a side-arm and a reflux condenser leading to the gas buret was placed $5 \mathrm{~mL}$ of a $1 \mathrm{M}$ solution of $\mathrm{HBCl}_{2}$ in $\mathrm{CH}_{2} \mathrm{Cl}_{2}(5 \mathrm{mmol})$ and the flask was immersed into a water bath at $25^{\circ} \mathrm{C}$. To this $0.33 \mathrm{~g}$ of isopropyl alcohol (5.5 mmol) was added dropwise. After the hydrogen evolution ceased. the mixture was stirred for an additional $30 \mathrm{~min}$. The ${ }^{11} \mathrm{~B}$ NMR spectrum of dichloroisopropoxyborane in $\mathrm{CH}_{2} \mathrm{Cl}_{2}$ showed a singlet at $\delta 18 \mathrm{ppm}$ relative to $\mathrm{BF}_{3} \cdot \mathrm{OEt}_{2}$

Reduction of Carbonyl Compounds. General Procedure. The following general reaction procedure was illustrative. Into the solution of dichloroisopropoxyborane in $\mathrm{CH}_{2} \mathrm{Cl}_{2}(5 \mathrm{mmol})$ just prepared as above $0.48 \mathrm{~g}$ of benzaldelyde (4.5 mmol) and tridecane (4.5 nmol) as an internal standard were injected. At the appropriate time intervals. an aliquot of the reaction mixture was withdrawn and quenched by addition of $2 \mathrm{~N} \mathrm{HCl}$. The aqueous layer was saturated with $\mathrm{K}_{2} \mathrm{CO}_{3}$ and the organic layer was dried over anhydrous $\mathrm{MgSO}_{4}$. GC analysis of the organic layer indicated the presence of benzyl alcohol in a yield of $100 \%$ at the period of $0.5 \mathrm{~h}$ or $24 \mathrm{~h}$.

Acknowledgments. This research was supported by the Yeungnam University research grants in 2007.

\section{References and Notes}

1. Cha. J. S.; Park, J. H. Bull. Korean Chem. Soc, 2002, 23. 1051; 1377.

2. (a) Meerwein. H.: Schmidt, R. Am. 1925, 44,221 . (b) Ponndorf. W. Angew. Chent 1926. 39. 138. (c) Verly. M. Bull. Soc. Chim. Rr. 1925.37.537. (d) Wilds. A. S. Org. React. 1944. 2. 178

3. Aldol condensations often are possible not only between two molecules of the aldehyde but also between the aldehyde and acetone formed. ${ }^{1}$

4. For review, see: (a) Cha, J. S. Org. Proc. Res. Devel. 2006, 1032 (b) Cha. J. S. Bull. Korean Chem. Soc. 2007. 28.2162. 